\title{
Multimodality therapy for locally advanced thymomas: A propensity score-matched cohort study from the European Society of Thoracic Surgeons Database
}

\author{
Giovanni Leuzzi, MD, ${ }^{\mathrm{a}}$ Gaetano Rocco, $\mathrm{PhD},{ }^{\mathrm{b}}$ Enrico Ruffini, $\mathrm{PhD},{ }^{\mathrm{c}}$ Isabella Sperduti, MS, \\ Frank Detterbeck, PhD, ${ }^{\mathrm{e}}$ Walter Weder, MD ${ }^{\mathrm{f}}$ Federico Venuta, $\mathrm{PhD},{ }^{\mathrm{g}}$ Dirk Van Raemdonck, PhD, \\ Pascal Thomas, PhD, ${ }^{i}$ Francesco Facciolo, MD, ${ }^{j}$ and the ESTS Thymic Working Group
}

\begin{abstract}
Objective: This study investigated the prognostic impact of multimodality therapies in locally advanced thymomas.

Methods: From January 1990 to January 2010, clinicopathological, surgical, and oncological features were retrospectively reviewed in a cohort of 370 MasaokaKoga stage III thymomas (World Health Organization classification A to B3) collected from 37 institutions. A multivariate Cox proportional hazard model was created to identify independent predictors of overall, cancer-specific (CSS), and relapse-free survivals. Furthermore, a propensity score-matching analysis for exposure to adjuvant (AT) therapy was generated.
\end{abstract}

Results: Induction therapy and AT were administered to 88 (24.9\%) and 245 $(69.4 \%)$ patients, respectively. Overall, 5- and 10-year overall survival, CSS, and relapse-free survivals were $82.8 \%, 88.4 \%$, and $80.0 \%$, and $68.9 \%$, $83.3 \%$, and $71.5 \%$, respectively. At multivariable analysis performed in the matched cohort, AT was confirmed as the strongest predictive factor for overall survival (hazard ratio, 2.83; 95\% confidence interval, 0.88-9.12; $P=.08$ ) and CSS (hazard ratio, $4.70 ; 95 \%$ confidence interval, $1.00-22.2 ; P=.05$ ). Pathologic $\mathrm{T}$ classification (according to International Association for the Study of Lung Cancer and International Thymic Malignancy Interest Group TNM staging proposal) was an independent factor for relapse (hazard ratio, 8.69; 95\% confidence interval, 1.08-70.04; $P=.04$ ). When CSS was adjusted for $\mathrm{T}$ classification, AT confirmed a significant survival advantage for pT3 tumors $(P=.04)$. On the other hand, for thymomas larger than $5 \mathrm{~cm}$, stratifying for tumor size and AT did not affect 5-year CSS $(P=.17)$.

Conclusions: Our results indicate that AT is beneficial for locally advanced thymomas, mainly for specific pathologic features (pT3 or tumor size smaller than $5 \mathrm{~cm}$ ). Further larger studies are needed to confirm these data. (J Thorac Cardiovasc Surg 2016;151:47-57)

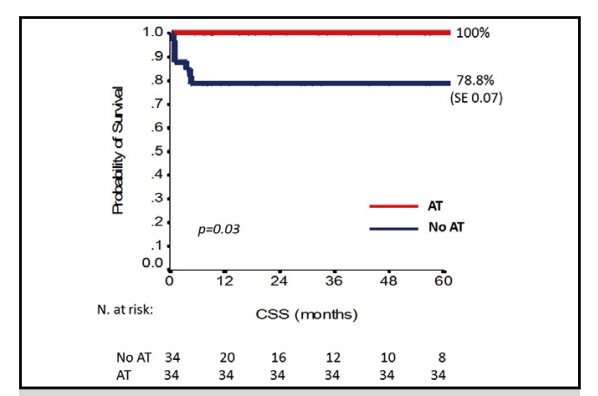

Cancer-specific survival according to the use of adjuvant therapy in stage III thymomas.

\section{Central Message}

Adjuvant therapy should be administered in locally advanced thymomas with specific pathologic features (pT3 or tumor size $<5 \mathrm{~cm}$ )

\section{Perspective}

Given the heterogeneity of stage III tumors, we assessed the effect of adjuvant therapy on outcome according to specific pathologic features (pT and tumor size) that may play a role postoperatively in the decision-making process on either adjuvant therapy or surveillance as well. These data may be considered for development of future trials on adjuvant therapy.

See Editorial Commentary page 58.

See Editorial page 20.
From the ${ }^{\mathrm{a} T h o r a c i c}$ Surgery Unit, IRCCS Istituto Nazionale dei Tumori Foundation,
Milan, Italy; the ${ }^{\mathrm{b}}$ Department of Thoracic Surgery, Istituto Nazionale Tumori,
IRCCS, Fondazione Pascale, Naples, Italy; the ${ }^{\mathrm{c}}$ Department of Surgery, Section
of Thoracic Surgery, University of Torino, Torino, Italy; ${ }^{\mathrm{d}}$ Scientific Direction, Re-
gina Elena National Cancer Institute-IFO, Rome, Italy; the ${ }^{\mathrm{e}}$ Department of Sur-
gery, Section of Thoracic Surgery, Yale University, New Haven, Conn; the
${ }^{\mathrm{f}}$ Department of Thoracic Surgery, University Hospital, Zurich, Switzerland; the
${ }^{\mathrm{g}}$ Department of Thoracic Surgery, University of Rome SAPIENZA, Policlinico
Umberto I, Fondazione Eleonora Lorilard Spencer Cenci, Rome, Italy; the ${ }^{\mathrm{h}}$ Depart-
ment of Thoracic Surgery, University Hospitals Leuven, Leuven, Belgium; the
${ }^{\mathrm{i}}$ Department of Thoracic Surgery, Aix-Marseille University, Marseille, France; and the ${ }^{\mathrm{j}}$ Department of Surgical Oncology, Thoracic Surgery Unit, Regina Elena National Cancer Institute-IFO, Rome, Italy.

Read at the 95th Annual Meeting of The American Association for Thoracic Surgery, Seattle, Washington, April 25-29, 2015.

Received for publication April 4, 2015; revisions received June 17, 2015; accepted for publication Aug 10, 2015; available ahead of print Sept 21, 2015.

Address for reprints: Giovanni Leuzzi, MD, Thoracic Surgery Unit, IRCCS Istituto Nazionale dei Tumori Foundation, Milan, Italy (E-mail: gio.leuzzi@yahoo.it). $0022-5223 / \$ 36.00$

Copyright (C) 2016 by The American Association for Thoracic Surgery http://dx.doi.org/10.1016/j.jtcvs.2015.08.034 


\section{Abbreviations and Acronyms: \\ TT = thymic tumor \\ OS = overall survival \\ LAT $=$ locally-advanced thymoma \\ IT = induction therapy \\ AT $=$ adjuvant therapy \\ ESTS $=$ European Society of Thoracic Surgeons \\ pT = Pathologic tumor invasion according to the proposed International Association for the Study of Lung Cancer and International Thymic Malignancy Interest Group TNM staging system \\ $\mathrm{HR}=$ hazard ratio \\ $\mathrm{CI}=$ confidence interval \\ CSS $=$ cancer-specific survival \\ RFS $=$ recurrence-free survival}

Supplemental material is available online.

Thymic tumors (TTs) are rare mediastinal malignancies accounting for $0.2 \%$ to $1.5 \%$ of all tumors and arising in approximately 1-5 patients/million population/y. ${ }^{1}$ Thymoma represents the most common histologic type, occurring in about $90 \%$ of the overall resected TTs. ${ }^{2}$ Specifically, patients with advanced-stage disease, occurring in $20 \%$ to $29 \%$ of all surgically treated thymomas, ${ }^{2,3}$ are likely to be subjected to a different range of radical resections $(50 \%-78 \%$ in the major surgical series $\left.{ }^{2-4}\right)$. Furthermore, a significant proportion (as great as $50 \%$ ) of patients with stage III thymomas have recurrence after surgery ${ }^{5-7}$; in these patients the pleura, lung, diaphragm, and tumor primary site are the most common sites of relapse. ${ }^{3,8}$ These data are significant if one takes into account that overall survival (OS) decreases with higher stage (III-IV) and after incomplete resection, whereas recurrence rate increases with greater tumor size, stages III and IV, and more aggressive histologic features. ${ }^{2,5}$

Reportedly, controversy still exists concerning the oncologic management of locally advanced thymomas (LATs). Although TTs have been documented to be chemoresponsive and radioresponsive, arguable and limited results have been reported when analyzing the outcome after induction therapy (IT)., ${ }^{9,10}$ Similarly, adjuvant therapy (AT) has been associated with variable survival after thymectomy. 2,8

In this setting, the aim of this study was to investigate the prognostic indicators in the specific subset of stage III thymomas with a large multicenter TT database. Furthermore,

we explored the impact of different multimodality treatments on survival.

\section{MATERIALS AND METHODS}

The European Society of Thoracic Surgeons (ESTS) thymic database project includes patients with TTs who underwent surgery from 1990 to 2010. Overall, 37 institutions joined the project: 29 from Europe, 5 from the United States and Canada, and 3 from Asia. Institutional review board approvals were obtained from each institution.

Among 2317 patients with TTs, we identified 370 cases with Masaoka-Koga stage III thymoma (World Health Organization [WHO] histologic type from A to B3). Thymic carcinomas and neuroendocrine TTs were excluded from the analysis.

The recorded data included demographic characteristics, presence of paraneoplastic syndromes, histologic type, 2004 WHO classification, tumor size, Masaoka-Koga staging system, ${ }^{11}$ year of surgery, type and extension of surgical procedure, completeness of resection, classification according to the International Association for the Study of Lung Cancer and International/Thymic Malignancy Interest Group TNM staging proposal (pT), ${ }^{12}$ administration of IT or AT, cause of death, and recurrence.

Preoperative staging was performed by computed tomographic scan in all cases, positron emission tomographic scan in most centers, and magnetic resonance imaging in selected cases mainly to asses major vascular involvement.

Histologic specimens were evaluated by pathologists experienced in mediastinal tumors. Patients undergoing surgery in or before 2004 has reclassification at each institution in accordance with the latest WHO histologic classification. ${ }^{1}$

Indications for IT and AT depended on the experience of each center and the multidisciplinary team evaluation. In particular, IT was administered mainly to those patients deemed to have potentially unresectable disease at preoperative workup. Chemotherapy for IT or AT varied according to different institutional treatment trials; as a rule, cisplatin-based regimens (mostly the combination of cisplatin, doxorubicin, and cyclophosphamide or the combination of cisplatin, doxorubicin, cyclophosphamide, and vincristine) were administered. In general, adjuvant radiotherapy was administered to a total dose of 40 to $60 \mathrm{~Gy}$.

Most institutions adopted a surveillance protocol that was based on a 3to 6-month computed tomographic scan for the first 2 years, followed by lifelong annual scans. With respect to clinical outcome, the follow-up data were collected from hospital medical notes and from interviews with patients, their next of kin, and their general practitioners. Surveillance information was available for 352 cases $(95.1 \%)$, with a median follow-up of 60 months (range 1-248 months).

\section{Statistical Analysis}

Descriptive statistics were used to summarize pertinent study information. Cutoffs of continuous variables were determined by performing the analysis by means of maximally selected log-rank statistics. The associations between variables were tested according to $\chi^{2}$, Student $t$, and Mann-Whitney (nonparametric) tests when appropriate. The hazard ratio (HR) and the confidence intervals (CI) were estimated for each variable by means of the Cox univariate model. A multivariate Cox proportional hazard model was also developed with stepwise regression (forward selection) by selecting those variables that were significant on univariate analysis. Entry and removal limits were $P=.10$ and $P=.15$, respectively. Survival was calculated by the Kaplan-Meier product-limit method from the date of surgery until the time of death from cancer (cancer-specific survival [CSS]), death from any cause (OS), or recurrence (recurrence-free survival [RFS]) at last follow-up. The log-rank test was used to assess differences between subgroups.

The effect of AT on survival has been explored in patients with R0 resection. To reduce the selection biases related to a nonrandomized cohort, 
TABLE 1. Clinical, surgical, and pathologic features of the overall sample

\begin{tabular}{|c|c|}
\hline \multicolumn{2}{|l|}{ Age $(y ; n=369)$} \\
\hline Median and range & $54(10-93)$ \\
\hline \multicolumn{2}{|l|}{$\operatorname{Sex}(n=370)$} \\
\hline Female & $195(52.7 \%)$ \\
\hline Male & $175(47.3 \%)$ \\
\hline \multicolumn{2}{|c|}{ Paraneoplastic syndromes $(\mathrm{n}=329)$} \\
\hline No & $199(60.5 \%)$ \\
\hline Myasthenia gravis & $120(36.5 \%)$ \\
\hline Others & $10(3.0 \%)$ \\
\hline \multicolumn{2}{|c|}{ WHO histologic type $(\mathrm{n}=366)$} \\
\hline A & $25(6.8 \%)$ \\
\hline $\mathrm{AB}$ & $37(10.1 \%)$ \\
\hline B1 & $47(12.8 \%)$ \\
\hline B2 & $131(35.8 \%)$ \\
\hline B3 & $126(34.5 \%)$ \\
\hline \multicolumn{2}{|c|}{ Surgical approach $(\mathrm{n}=320)$} \\
\hline Sternotomy & $274(85.6 \%)$ \\
\hline Thoracotomy & $36(11.3 \%)$ \\
\hline VATS or robotic & $10(3.1 \%)$ \\
\hline \multicolumn{2}{|c|}{ Kind of thymectomy $(\mathrm{n}=264)$} \\
\hline Radical & $254(96.2 \%)$ \\
\hline Partial & $10(3.8 \%)$ \\
\hline \multicolumn{2}{|c|}{ Extent of resection $(n=242)$} \\
\hline Pleura & $62(25.6 \%)$ \\
\hline Lung & $130(53.7 \%)$ \\
\hline Pericardium & $97(40.1 \%)$ \\
\hline Diaphragm & $3(1.2 \%)$ \\
\hline Phrenic nerve & $29(12.0 \%)$ \\
\hline Vessel & $33(13.6 \%)$ \\
\hline Combined* & $9(3.7 \%)$ \\
\hline \multicolumn{2}{|c|}{ Pathologic resection status $(\mathrm{n}=348)$} \\
\hline R0 & $258(74.1 \%)$ \\
\hline $\mathrm{R} 1$ & $53(15.2 \%)$ \\
\hline $\mathrm{R} 2$ & $37(10.7 \%)$ \\
\hline \multicolumn{2}{|c|}{ Pathologic invasion $(\mathrm{n}=245)$} \\
\hline Pleura & $66(26.9 \%)$ \\
\hline Lung & $121(49.4 \%)$ \\
\hline Pericardium & $116(47.3 \%)$ \\
\hline Diaphragm & $3(1.2 \%)$ \\
\hline Phrenic nerve & $26(10.6 \%)$ \\
\hline Vessel & $37(15.1 \%)$ \\
\hline Multiple (>2) & $90(36.7 \%)$ \\
\hline \multicolumn{2}{|l|}{ pT $(\mathrm{n}=246)$} \\
\hline 2 & $80(32.5 \%)$ \\
\hline 3 & $166(67.5 \%)$ \\
\hline \multicolumn{2}{|c|}{ Tumor size $(\mathrm{cm} ; \mathrm{n}=255)$} \\
\hline Median and range & $5(1-21)$ \\
\hline \multicolumn{2}{|l|}{$\mathrm{IT}(\mathrm{n}=328)$} \\
\hline None & $240(73.2 \%)$ \\
\hline CT & $67(20.4 \%)$ \\
\hline CT-RT & $17(5.2 \%)$ \\
\hline RT & $4(1.2 \%)$ \\
\hline \multicolumn{2}{|l|}{$\mathrm{AT}(\mathrm{n}=351)$} \\
\hline None & $106(30.2 \%)$ \\
\hline CT-RT & $76(21.7 \%)$ \\
\hline
\end{tabular}

TABLE 1. Continued

\begin{tabular}{lr}
\hline CT & $12(3.4 \%)$ \\
RT & $157(44.7 \%)$ \\
Treatment strategy $(\mathrm{n}=353)$ & \\
Surgery alone & $66(18.7 \%)$ \\
IT + surgery & $42(11.9 \%)$ \\
Surgery + AT & $199(56.4 \%)$ \\
IT + Surgery + AT & $46(13.0 \%)$ \\
\hline
\end{tabular}

All data represent number and percentage unless otherwise specified. $W H O$, World Health Organization; VATS, video-assisted thoracoscopic surgery; $p T$, pathologic tumor invasion according to the proposed TNM staging system; $I T$, induction therapy; $C T$, chemotherapy; $R T$, radiotherapy; $A T$, adjuvant therapy. *At least 3 organs resected.

a propensity score for the likelihood of receiving AT was calculated from 7 covariates: age, sex, autoimmune syndromes, tumor size, WHO histologic type, T classification, and administration of IT. After exclusions, 144 patients were identified (unmatched sample). By using a 1:1 nearest neighbor matching algorithm that pairs patients with the closest propensity scores within a defined limit (calipers of width equal to 0.2 ), the propensity score yielded 2 well-matched cohorts of 34 patients (logistic regression estimation algorithm). Multivariable Cox proportional hazard models were further performed in the final sample.

SPSS software (SPSS version 21.0; IBM Corporation, Armonk, NY) and $\mathrm{R}$ ( $\mathrm{R}$ version 3.2.2, 2014; The R Foundation, Vienna, Austria) were used for all statistical evaluations.

\section{RESULTS}

Clinical, surgical, and pathologic features are illustrated in Table 1. There were $195(52.7 \%)$ male patients, and the median age was 54 years (range 10-93 years). A paraneoplastic syndrome was observed in 130 of 329 cases $(39.5 \%)$, with myasthenia gravis being the most frequent (120 patients). Thymoma B2 was the most common histologic type $(131 ; 35.8 \%)$. Median tumor size at surgery was $5 \mathrm{~cm}$ (range, $1-21 \mathrm{~cm}$ ). Sternotomy $(85.6 \%)$ and radical thymectomy $(96.2 \%)$ were the preferred procedures for most surgeons. With regard to surgical extension, the main resected organs were the lung $(53.7 \%)$ and the pericardium $(40.1 \%)$. A radical (R0) resection was achieved in 258 of 348 patients $(74.1 \%)$, whereas microscopic (R1) and macroscopic (R2) incomplete resections were found in $53(15.2 \%)$ and $37(10.7 \%)$ cases, respectively. Final pathologic examination confirmed multiple organ involvement in $36.7 \%$ of cases, with the lung $(49.4 \%)$ and pericardium $(47.3 \%)$ the most affected.

Among 353 patients with available data on concurrent oncologic treatments, IT and AT were administered to 88 $(24.9 \%)$ and $245(69.4 \%)$ patients, respectively. According to the type of therapy, 4 treatment modalities were adopted and can be summarized as follows: surgery alone (18.7\%), IT plus surgery $(11.9 \%)$, trimodality therapy (IT followed by surgery and AT; $13.0 \%$ ), and primary surgery plus AT $(56.4 \%)$. With regard to the IT subset, chemotherapy alone was administered to most patients $(67 ; 76.1 \%)$. Relative to those patients not receiving neoadjuvant therapy, patients 
TABLE 2. Comparison of clinical, surgical, and pathologic features according to the administration of induction or adjuvant therapy in the unmatched and matched sample

\begin{tabular}{|c|c|c|c|c|c|c|c|c|c|}
\hline & \multicolumn{6}{|c|}{ Unmatched samples } & \multicolumn{3}{|c|}{ Matched sample ( $n=34$ /group) } \\
\hline & IT & No IT & $P$ value & AT & No AT & $P$ value & $\mathbf{A T}(\%)$ & No AT $(\%)$ & $P$ value \\
\hline \multicolumn{10}{|l|}{ Age (y) } \\
\hline$<54$ & $56(63.6 \%)$ & $110(45.3 \%)$ & .004 & $137(55.9 \%)$ & $43(40.6 \%)$ & .008 & $20(58.8)$ & $15(44.1)$ & .23 \\
\hline$>54$ & $32(36.4 \%)$ & $133(54.7 \%)$ & & $108(44.1 \%)$ & $63(59.4 \%)$ & & $14(41.2)$ & $19(55.9)$ & \\
\hline \multicolumn{10}{|l|}{ Sex } \\
\hline Female & $41(46.6 \%)$ & $115(47.3 \%)$ & .91 & $106(43.3 \%)$ & $57(53.8 \%)$ & .07 & $24(70.6)$ & $19(55.9)$ & .21 \\
\hline Male & $47(53.4 \%)$ & $128(52.7 \%)$ & & $139(56.7 \%)$ & $49(46.2 \%)$ & & $10(29.4)$ & $15(44.1)$ & \\
\hline \multicolumn{10}{|c|}{ Paraneoplastic syndrome } \\
\hline No & $63(78.8 \%)$ & $128(53.6 \%)$ & $<.0001$ & $130(58.0 \%)$ & $60(64.5 \%)$ & .28 & $12(35.3)$ & $17(50.0)$ & .22 \\
\hline Yes & $17(21.2 \%)$ & $111(46.4 \%)$ & & $94(42.0 \%)$ & $33(35.5 \%)$ & & $22(64.7)$ & $17(50.0)$ & \\
\hline \multicolumn{10}{|l|}{ WHO histologic type } \\
\hline A & $1(1.1 \%)$ & $18(7.5 \%)$ & .05 & $10(4.1 \%)$ & $11(10.6 \%)$ & .008 & & & .78 \\
\hline $\mathrm{AB}$ & $4(4.6 \%)$ & $27(11.2 \%)$ & & $23(9.4 \%)$ & $12(11.5 \%)$ & & & & \\
\hline B1 & $10(11.5 \%)$ & $33(13.7 \%)$ & & $32(13.1 \%)$ & $13(12.5 \%)$ & & $9(26.5)^{*}$ & $8(23.5)^{*}$ & \\
\hline $\mathrm{B} 2$ & $38(43.7 \%)$ & $83(34.4 \%)$ & & $85(34.8 \%)$ & $42(40.4 \%)$ & & & & \\
\hline B3 & $34(39.1 \%)$ & $34(39.1 \%)$ & & $94(38.5 \%)$ & $26(25.0 \%)$ & & $25(73.5) \dagger$ & $26(76.4) \dagger$ & \\
\hline \multicolumn{10}{|l|}{ Kind of thymectomy } \\
\hline Radical & $64(91.4 \%)$ & $180(97.8 \%)$ & .03 & $179(96.2 \%)$ & $72(96.0 \%)$ & .93 & & & \\
\hline Partial & $6(8.6 \%)$ & $4(2.2 \%)$ & & $7(3.8 \%)$ & $3(4.0 \%)$ & & & & \\
\hline \multicolumn{10}{|c|}{ Pathologic resection status } \\
\hline R0 & $53(65.4 \%)$ & $187(79.9 \%)$ & .01 & $182(76.8 \%)$ & $71(71.7 \%)$ & .61 & & & \\
\hline $\mathrm{R} 1$ & $15(18.5 \%)$ & $25(10.7 \%)$ & & $32(13.5 \%)$ & $16(16.2 \%)$ & & & & \\
\hline $\mathrm{R} 2$ & $13(16.1 \%)$ & $22(9.4 \%)$ & & $23(9.7 \%)$ & $12(12.1 \%)$ & & & & \\
\hline \multicolumn{10}{|l|}{$\mathrm{pT}$} \\
\hline 2 & $16(25.0 \%)$ & $49(33.6 \%)$ & .09 & $61(38.4 \%)$ & $13(18.6 \%)$ & .003 & $11(32.4)$ & $9(26.5)$ & .60 \\
\hline 3 & $48(75.0 \%)$ & $97(66.4 \%)$ & & $98(61.6 \%)$ & $57(81.4 \%)$ & & $23(67.6)$ & $25(73.5)$ & \\
\hline \multicolumn{10}{|l|}{ Pathologic invasion } \\
\hline Pleura & $9(15.8 \%)$ & $56(30.8 \%)$ & .03 & $49(27.4 \%)$ & $15(25.4 \%)$ & .77 & & & \\
\hline Lung & $27(47.4 \%)$ & $93(51.1 \%)$ & .62 & $90(50.3 \%)$ & $29(49.2 \%)$ & .88 & & & \\
\hline Pericardium & $19(33.3 \%)$ & $95(52.2 \%)$ & .01 & $87(48.6 \%)$ & $26(44.1 \%)$ & .54 & & & \\
\hline Diaphragm & - & $3(1.6 \%)$ & .33 & $3(1.7 \%)$ & - & .32 & & & \\
\hline Phrenic nerve & $5(8.8 \%)$ & $21(11.5 \%)$ & .56 & $21(11.7 \%)$ & $4(6.8 \%)$ & .28 & & & \\
\hline Vessel & $19(33.3 \%)$ & $17(9.3 \%)$ & $<.0001$ & $24(13.4 \%)$ & $12(20.3 \%)$ & .20 & & & \\
\hline \multicolumn{10}{|l|}{ Tumor size (cm) } \\
\hline Median and range & $5(2-17)$ & $5(1-21)$ & .27 & $5(2-21)$ & $6(1-17)$ & .001 & & & .61 \\
\hline$<5$ & & & & & & & $23(67.6)$ & $21(61.8)$ & \\
\hline$>5$ & & & & & & & $11(32.4)$ & $13(38.2)$ & \\
\hline IT & - & - & - & $48(19.4 \%)$ & $40(37.3 \%)$ & .13 & $9(47.4)$ & $10(52.6)$ & .79 \\
\hline
\end{tabular}

Data represent numbers and percentages of patients except as noted. IT, Induction therapy; $A T$, adjuvant therapy; WHO, World Health Organization; $p T$, pathologic tumor invasion according to the proposed TNM staging system. *Low-grade World Health Organization histologic type. †High-grade World Health Organization histologic type.

undergoing IT were younger $(P=.004)$, more frequently had presenting paraneoplastic syndromes $(P<.001)$, had worse WHO histologic type $(P=.05)$, and were more often subjected to subtotal thymus gland excision $(P=.03)$, yielding higher rates of incomplete resection $(P=.01$; Table 2). With regard to AT, surgery was followed by radiotherapy alone in most cases $(157 ; 64.1 \%)$. The main differences between patients receiving AT and those who did not are listed in Table 2.

At the end of the study period, 81 patients had died, 51 of cancer-related causes. A relapse was reported in $63(17.5 \%)$ cases: among 59 patients with available data on recurrence location, a local relapse (pleura and tumor bed in most cases) was observed in 45 cases, whereas distant metastases (mainly pulmonary) occurred in 14 cases. According to tumor size, thymomas larger than $5 \mathrm{~cm}$ were mainly associated with local recurrence than with distant recurrence (for tumors smaller than $5 \mathrm{~cm}$, local relapse, $66.7 \%$; distant relapse, $33.3 \%$; for tumors larger than $5 \mathrm{~cm}$, local relapse, $85.7 \%$; distant relapse, $14.3 \% ; P=.006$ ).

Overall, the 5- and 10-year OS, CSS, and RFS were $82.8 \%, 88.4 \%$, and $80.0 \%$, and $68.9 \%, 83.3 \%$, and 

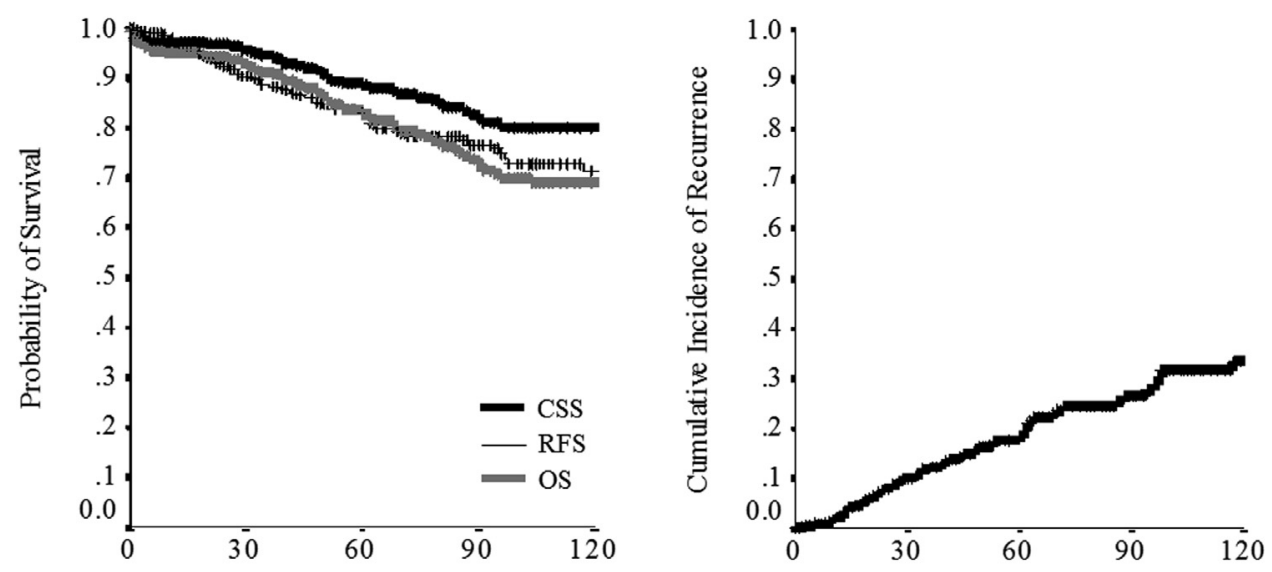

A

Months

B

Months

FIGURE 1. A, Overall $(O S)$, cancer-specific $(C S S)$, and recurrence-free $(R F S)$ survivals of the total sample. B, Cumulative incidence of relapse in the total sample.

$71.5 \%$, respectively (Figure 1, A). The 5- and 10-year cumulative incidences of recurrence were, respectively, $20 \%$ and $28.5 \%$ (Figure 1, B). The evaluated prognostic factors for survival in statistical analysis were as follows: age, sex, associated paraneoplastic syndromes, WHO histologic type, tumor size, kind of thymectomy, pT, organ involved at pathologic examination, completeness of resection, administration of IT or AT, and type of multimodality therapy. The results on univariate and multivariable analyses are reported in Table 3. Multivariate analysis showed that age (HR, 1.80; 95\% CI, 1.11-2.90; $P=.016$ ), R0 resection (HR, 2.38; 95\% CI, 1.44-3.92; $P=.001)$, and AT (HR, 2.02; 95\% CI, 1.23-3.31; $P=.005)$ independently predicted OS. Analysis on CSS confirmed R0 resection (HR, 2.15; 95\% CI, 1.16-4.00; $P=.015)$ and AT (HR, 2.44; 95\% CI, 1.32-4.48; $P=.004)$ as independent outcome predictors. With regard to RFS, pathologic tumor invasion (HR, 2.49; $95 \% \mathrm{CI}$, 1.19-5.21; $P=.016$ ) was the unique and significant predictive factor for relapse in the multivariate Cox regression model.

As discussed previously, a propensity score for the likelihood of receiving AT in R0 patients was calculated from 7 covariates: age, sex, autoimmune syndromes, tumor size, WHO histologic type, pT classification, and administration of IT. The propensity score yielded a balanced cohort of 68 patients (Table 2 and Figure 2). In the Cox multivariable analyses, AT was confirmed as the strongest predictive factor for OS (HR, 2.83; 95\% CI, $0.88-9.12 ; P=.08)$ and CSS (HR, 4.70; 95\% CI, 1.0022.2; $P=.05$; Figure 3). Furthermore, pT classification was the unique independent factor for relapse (HR, 8.69; 95\% CI, 1.08-70.04; $P=.04$; Table 3 ).

According to treatment strategy in the total sample, a worse outcome was reported for those patients undergoing surgery alone (5-year CSS, $80.7 \%, P=.007$; Figure 4). In the matched sample, patients receiving IT had a similar 5 -year CSS to those undergoing primary surgery $(84.2 \%$ vs $91.4 \% ; P=.61)$. We further analyzed the impact of AT on survival according to the pathologic cancer features (pT and tumor size) and kind of postop therapy. When CSS was adjusted for microscopic invasion (according to pT classification), AT conferred a significant survival advantage for pT3 tumors (pT2: $P=.13$; pT3: $P=.04$, Figure 4). Similarly, an outcome benefit of AT was reported in the subset of smaller LATs $(P=.04)$. On the other hand, for thymomas larger than $5 \mathrm{~cm}$, stratifying for tumor size and AT did not affect 5-year CSS $(P=.17$; Figure 4). Finally, according to the kind of postoperative therapy, administration of postoperative radiotherapy (alone or in combination with chemotherapy) resulted in improved CSS relative to those not receiving radiotherapy $(P=.03$; Figure 4).

\section{DISCUSSION}

Masaoka-Koga stage III accounts for those TTs characterized by the invasion of different intrathoracic structures, regardless of other specific pathologic features. This high variability in clinicopathologic behavior has long represented the main obstacle for most oncologists and surgeons in assessing the optimal therapeutic strategy in LATs; the real effect of multimodality therapies thus still remains controversial in such cases. Furthermore, as reported by a recent survey from the ESTS, the rarity of TTs has so far limited the chance to set homogeneous management protocols. ${ }^{13}$

In the literature, the completeness of resection has been extensively evaluated in several surgical series and reported as the best prognosticator. ${ }^{5,14}$ In the setting of LATs, the rate 
TABLE 3. Univariate and multivariate analysis for overall, cancer-specific and recurrence-free survival in the total and matched sample

\begin{tabular}{|c|c|c|c|c|c|c|c|c|c|c|c|c|c|c|c|}
\hline \multirow[b]{3}{*}{ Variables } & \multicolumn{5}{|c|}{ Overall survival } & \multicolumn{5}{|c|}{ Cancer-specific survival } & \multicolumn{5}{|c|}{ Recurrence-free survival } \\
\hline & \multirow{2}{*}{$\begin{array}{c}\mathrm{UV} \\
P \\
\text { value }\end{array}$} & \multicolumn{2}{|l|}{ MV* } & \multicolumn{2}{|l|}{$\mathbf{M V} \dagger$} & \multirow{2}{*}{$\frac{\mathrm{UV}}{P}$} & \multicolumn{2}{|l|}{ MV* } & \multicolumn{2}{|l|}{$\mathbf{M V} \dagger$} & \multirow{2}{*}{$\begin{array}{c}\mathrm{UV} \\
P \\
\text { value }\end{array}$} & \multicolumn{2}{|l|}{ MV* } & \multicolumn{2}{|l|}{$\mathbf{M V} \dagger$} \\
\hline & & $\begin{array}{c}\text { HR } \\
{[95 \% \mathrm{CI}]}\end{array}$ & $\begin{array}{c}P \\
\text { value }\end{array}$ & $\begin{array}{c}\text { HR } \\
{[95 \% \mathrm{CI}]}\end{array}$ & $\begin{array}{c}P \\
\text { value }\end{array}$ & & $\begin{array}{c}\text { HR } \\
{[95 \% \mathrm{CI}]}\end{array}$ & $\begin{array}{c}P \\
\text { value }\end{array}$ & $\begin{array}{c}\text { HR } \\
{[95 \% \mathrm{CI}]}\end{array}$ & $\begin{array}{c}P \\
\text { value }\end{array}$ & & $\begin{array}{c}\text { HR } \\
{[95 \% \mathrm{CI}]}\end{array}$ & $\begin{array}{c}P \\
\text { value }\end{array}$ & $\begin{array}{c}\text { HR } \\
{[95 \% \mathrm{CI}]}\end{array}$ & $\begin{array}{c}P \\
\text { value }\end{array}$ \\
\hline \multicolumn{16}{|l|}{$\overline{\operatorname{Sex}}$} \\
\hline Male vs female & .39 & & & & & .29 & & & & & .72 & & & & \\
\hline \multicolumn{16}{|l|}{ Age $(y)$} \\
\hline$<54$ vs $>54$ & .022 & $\begin{array}{l}1.80 \\
\quad[1.11-2.90]\end{array}$ & .016 & $\begin{array}{l}3.73 \\
\quad[1.04-13.4]\end{array}$ & .04 & .14 & & & & & .28 & & & & \\
\hline \multicolumn{16}{|c|}{ Paraneoplastic syndromes } \\
\hline Yes vs no & .08 & & & & & .49 & & & & & .88 & & & & \\
\hline \multicolumn{16}{|l|}{$\begin{array}{l}\text { WHO histologic } \\
\text { type }\end{array}$} \\
\hline $\begin{array}{l}\text { B2-B3 vs } \\
\text { A-AB-B1 }\end{array}$ & .42 & & & & & .56 & & & & & .16 & & & & \\
\hline \multicolumn{16}{|l|}{ Tumor size $(\mathrm{cm})$} \\
\hline$>5$ vs $<5$ & .28 & & & & & .22 & & & & & .015 & & & & \\
\hline \multicolumn{16}{|c|}{ Kind of thymectomy } \\
\hline Partial vs total & .15 & & & & & & & & & & .87 & & & & \\
\hline \multicolumn{16}{|l|}{ Resection status } \\
\hline $\mathrm{R}+\mathrm{vs} \mathrm{R} 0$ & $<.0001$ & $\begin{array}{l}2.38 \\
\quad[1.44-3.92]\end{array}$ & .001 & & & .002 & $\begin{array}{l}2.15 \\
\quad[1.16-4.00]\end{array}$ & .015 & & & .78 & & & & \\
\hline \multicolumn{16}{|l|}{ Organ invasion } \\
\hline Pleura & .47 & & & & & .80 & & & & & .60 & & & & \\
\hline Lung & .40 & & & & & .38 & & & & & .58 & & & & \\
\hline Pericardium & .91 & & & & & .70 & & & & & .85 & & & & \\
\hline Vessel & .85 & & & & & .45 & & & & & .79 & & & & \\
\hline Diaphragm & .76 & & & & & .28 & & & & & .97 & & & & \\
\hline Phrenic nerve & .28 & & & & & .34 & & & & & .38 & & & & \\
\hline \multicolumn{16}{|l|}{ pT } \\
\hline $\mathrm{T} 3$ vs $\mathrm{T} 2$ & .23 & & & & & .15 & & & & & .016 & $\begin{array}{l}2.49 \\
\quad[1.19-5.21]\end{array}$ & .016 & $\begin{array}{l}8.69 \\
\quad[1.08-70.04]\end{array}$ & .04 \\
\hline \multicolumn{16}{|l|}{ IT } \\
\hline No vs yes & .43 & & & & & .82 & & & & & .31 & & & & \\
\hline \multicolumn{16}{|l|}{ AT } \\
\hline No vs yes & $<.0001$ & $\begin{array}{l}2.02 \\
\quad[1.23-3.31]\end{array}$ & .005 & $\begin{array}{l}2.83 \\
\quad[0.88-9.12]\end{array}$ & .08 & .001 & $\begin{array}{l}2.44 \\
\quad[1.32-4.48]\end{array}$ & .004 & $\begin{array}{l}4.70 \\
\quad[1.00-22.20]\end{array}$ & .05 & .19 & & & & \\
\hline Multimodality ther & rapy & & & & & & & & & & & & & & \\
\hline Surgery + AT & .04 & & & & & .05 & & & & & .59 & & & & \\
\hline IT + surgery & .72 & & & & & .99 & & & & & .90 & & & & \\
\hline IT + surgery + & .03 & & & & & .005 & & & & & .96 & & & & \\
\hline
\end{tabular}

$\overline{U V}$, Univariate analysis; $M V$, multivariate analysis; $H R$, hazard ratio; $C I$, confidence interval; $W H O$, World Health Organization; $p T$, pathologic tumor invasion according to the proposed TNM staging system; $I T$, induction therapy; $A T$, adjuvant therapy. *Unmatched cohort. $†$ Matched cohort.

of radical resection is highly variable ${ }^{3,4,15}(74.1 \%$ in our series), given the technical difficulties encountered for large tumor dimension ${ }^{2}$ or involvement of mediastinal structures (including major blood vessels, pericardium, or other vital structures). This issue is of particular relevance when considering that an incomplete resection or debulking procedure could not improve survival relative to biopsy alone, leading to increased recurrence rates and poorer prognosis. ${ }^{16}$ In this context, the administration of multimodality therapies has gained growing interest among physicians through the years because of the welldocumented chemoresponsiveness and radioresponsiveness of TTs. With respect to the administration of IT, pioneering experiences were first published in the 1980s by Giaccone and colleagues, ${ }^{17}$ and until now few studies and clinical trials on neoadjuvant therapy have been reported in the literature. ${ }^{9,10,18-20}$ From a recent review by Kondo, ${ }^{20}$ the complete resection rate after IT varies between $22 \%$ and $92 \%$, although this difference may reflect the kind of cancer invasiveness before IT or the surgeon's ability in performing extensive surgery. Moreover, analyzing the impact of IT on outcome, the 7-year RFS and OS were approximately $70 \%$ and more than $70 \%$, respectively, in the subset of LATs, ${ }^{14}$ similar to the results reported in our series. These data suggest that resectability and survival may improve after IT in patients with stage III and IV disease ${ }^{21}$; however, 


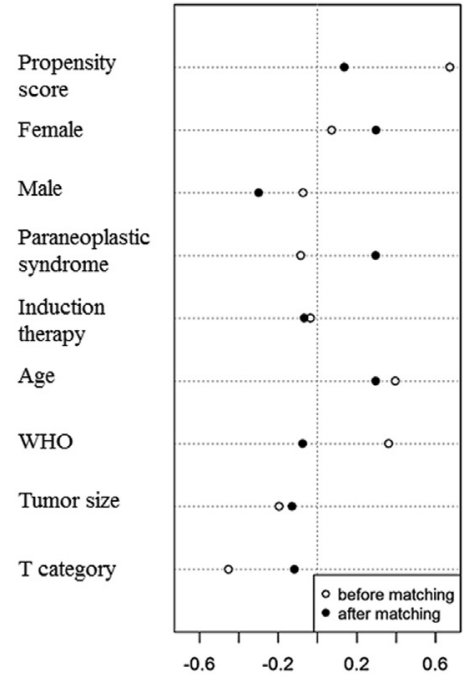

A

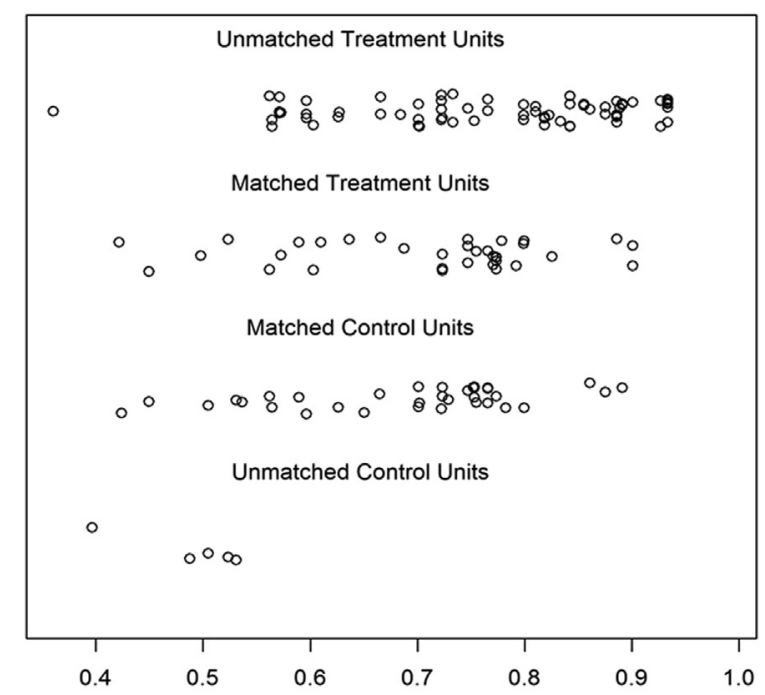

B

FIGURE 2. A, Forest plot of subgroup analysis for adjuvant versus no adjuvant therapy comparison, adjusted for propensity score. B, Distribution of propensity scores. WHO, World Health Organization.

the reviewed studies were performed on small cohorts. Furthermore, these articles analyzed only the feasibility of multimodality therapy without performing a true comparison between different treatment strategies. ${ }^{9,10,19,20}$ In our series, administration of IT did not seem to affect survival in the unmatched and matched cohorts in terms of either CSS or RFS. Our comparative analysis did, however, demonstrate a biased selection (according to age, WHO histologic type and tumor invasiveness) and a lower radical resection rate among patients receiving

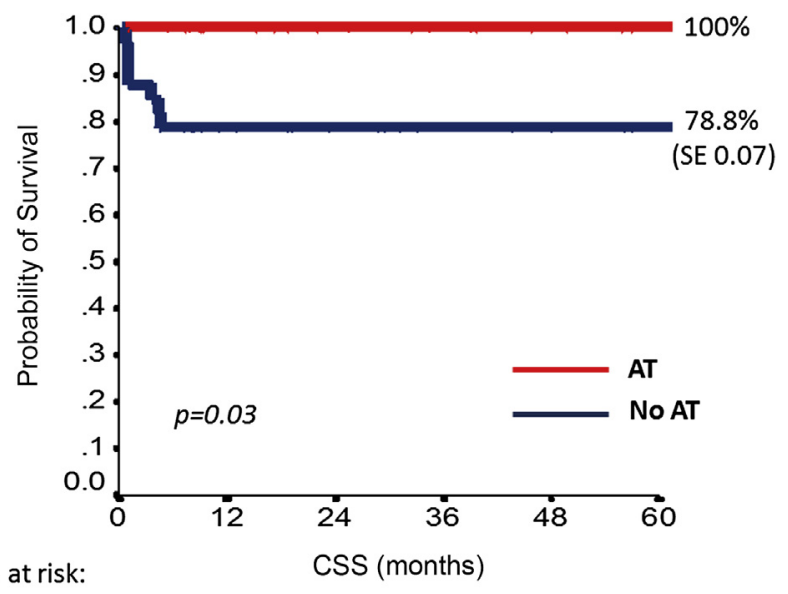

$\begin{array}{llllllr}\text { No AT } & 34 & 20 & 16 & 12 & 10 & 8 \\ \text { AT } & 34 & 34 & 34 & 34 & 34 & 34\end{array}$

FIGURE 3. Cancer-specific survival ( $C S S$ ) according to administration of adjuvant therapy $(A T)$ in the matched sample. $S E$, Standard error. neoadjuvant therapy. In addition, we did not have sufficient data on the kind of indication for IT and the radiologic response and downstaging rates, and as a result the real estimation of its efficacy may be unpowered. On the basis of our data, we deem that there is no appropriate comparison group (eg, patients with potentially unresectable disease undergoing immediate surgery) or way to propensity match patients undergoing IT. For these reasons, we advocate the need for further trials to investigate better the role of IT on outcome and to define the optimal candidates to receive such treatment. In this setting, a recent analysis on 23 out of 133 patients with incomplete resection has estimated the preoperative tumor features (degree of abutment of adjacent vessels and pleural nodularity) predicting the risk of leaving residual disease. ${ }^{22}$ In our opinion, the identification of TTs with these radiologic characteristics is of paramount importance and may help to select those patients who might benefit from neoadjuvant therapy in future randomized, controlled trials.

In literature, the common practice on AT still remains controversial. Specifically, some advocate AT for all patients undergoing thymectomy, regardless of tumor features ${ }^{23}$ or the data on completeness of resection or pathologic stage. ${ }^{24}$ So far, prospective clinical trials on AT are limited, ${ }^{25,26}$ and in some cases biased by including thymoma along with thymic carcinoma. ${ }^{25}$ On the other hand, it is worthy of note that AT (mainly mediastinal radiotherapy) may be associated with adverse effects, including secondary malignancies, pulmonary fibrosis, coronary artery disease, cardiac valvular fibrosis, pericardial disease, and esophageal strictures. ${ }^{27,28}$ 

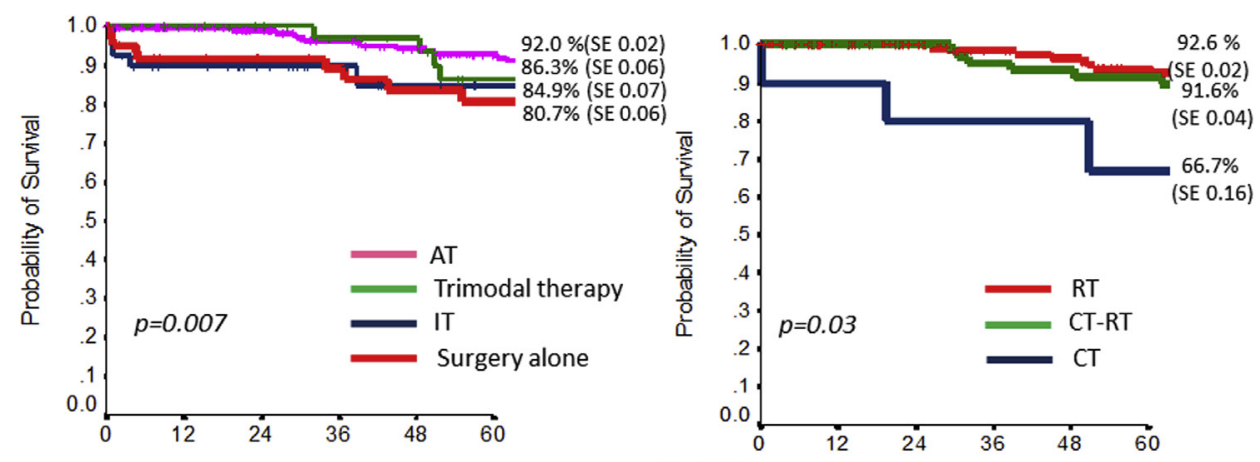

\begin{tabular}{lcccccc} 
N. at risk: & \multicolumn{5}{c}{ CSS (months) } \\
AT & 195 & 175 & 162 & 145 & 133 & 112 \\
Trimodal & 45 & 41 & 34 & 31 & 28 & 22 \\
IT & 40 & 31 & 25 & 19 & 15 & 11 \\
Surgery & 62 & 47 & 40 & 34 & 28 & 24
\end{tabular}

A

T2
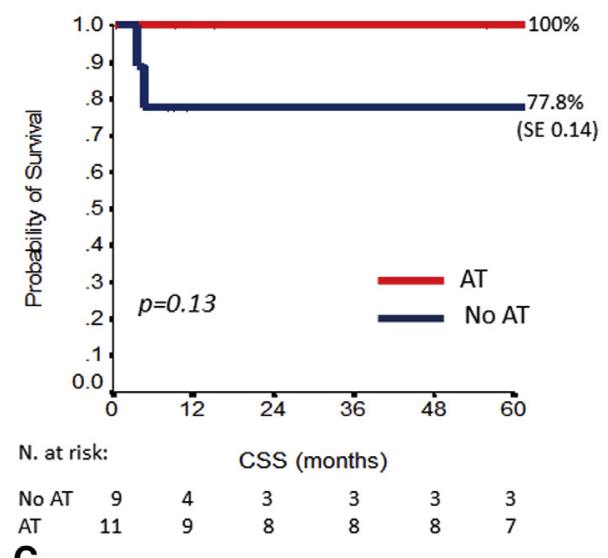

C

T-size $<5 \mathrm{~cm}$
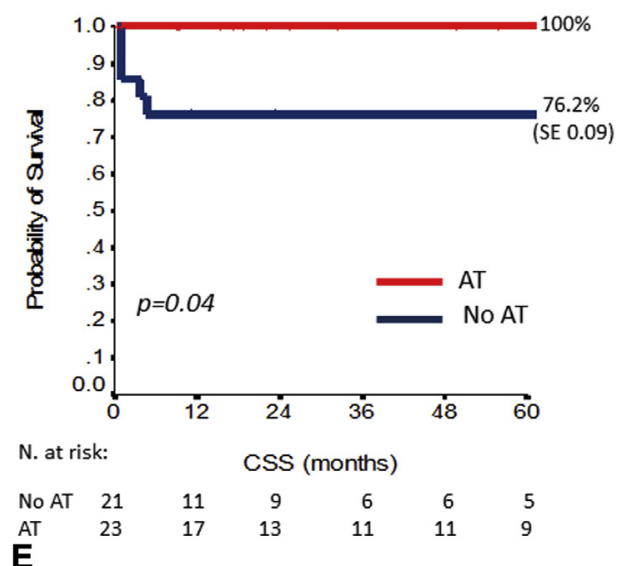

N. at risk:

CSS (months)

$\begin{array}{lllllll}\text { RT } & 157 & 140 & 126 & 112 & 104 & 85\end{array}$

$\begin{array}{lclllll}\text { CT-RT } & 73 & 67 & 62 & 57 & 49 & 46 \\ \text { CT } & 10 & 9 & 8 & 7 & 7 & 3\end{array}$

B

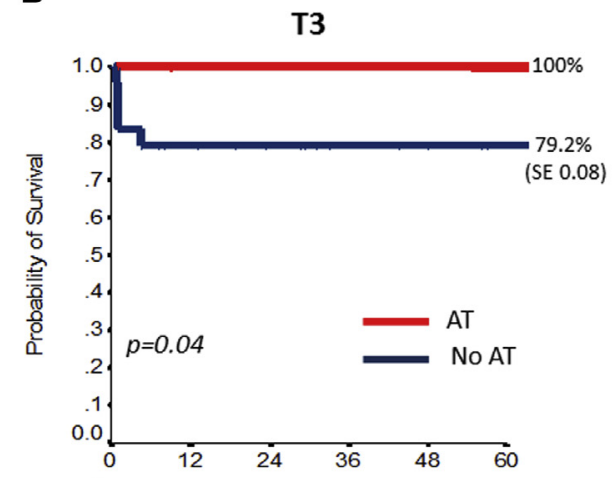

N. at risk:

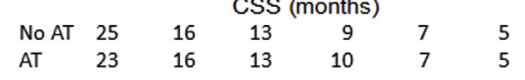

。

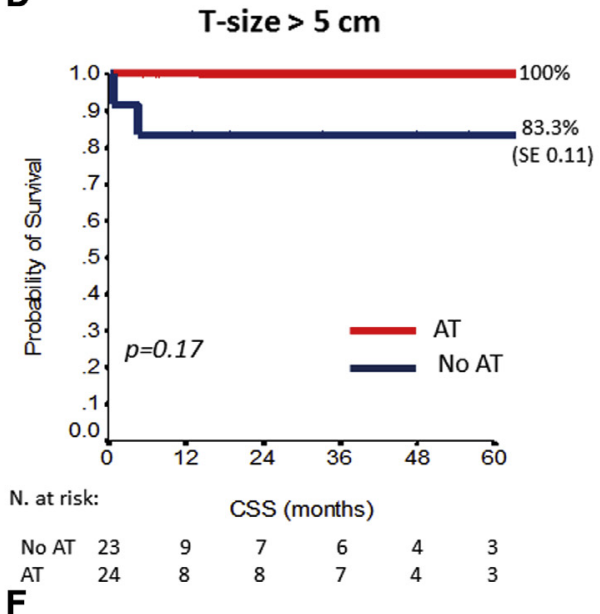

FIGURE 4. A, Cancer-specific survival (CSS) according to treatment strategy (induction therapy [IT] vs adjuvant therapy [AT]) in the total sample. $\mathrm{B}$, Cancer-specific survival according to the kind of postoperative treatment in the total sample. $\mathrm{C}$ and $\mathrm{D}$, Impact of adjuvant therapy on cancer-specific survival according to pT classification in the matched sample. E and F, Impact of adjuvant therapy on cancer-specific survival according to tumor size in the matched. $R T$, Radiotherapy; $S E$, Standard error.

Currently, some evidence indicates that there is no significant survival advantage associated with the use of AT (especially radiotherapy) after resection of LATs.
Kondo and associates ${ }^{14}$ found that prophylactic postoperative radiotherapy neither prevented recurrence nor increased survival after complete removal of stages II 
to IV TTs. Similarly, Korst and colleagues ${ }^{8}$ did not report a survival advantage for the use of radiotherapy in completely resected stage II to III thymomas. A recent Japanese experience with 270 stage III thymomas revealed that postoperative radiotherapy was not associated with better OS and RFS, ${ }^{29}$ revealing a declining trend in administering this therapy in Japan as well. On the other hand, in a previous ESTS analysis, the overall effect of AT after R0 resection on OS was significantly beneficial, although an effect modification was not in evidence after stratification for specific patient subsets. ${ }^{2}$ These results are similar to the Surveillance, Epidemiology, and End Results Program database analysis, ${ }^{30}$ which reported a significantly improved CSS after administration of postoperative radiotherapy relative to TTs undergoing surgery alone. Partially in line with the latter work (which lacks data on the use of postoperative chemotherapy), our multivariable analysis and propensity score matching suggested that the whole administration of AT was beneficial in the overall sample, with specific survival differences according to the type of postoperative treatment. Also, it should be noted that counting radiotherapy along with administration (or not) of chemotherapy as a single variable (AT) resulted in a statistical difference regarding the effect on OS or CSS and RFS. In fact, although mediastinal radiotherapy has been reported to prevent local recurrence, ${ }^{31}$ it did not control pleural dissemination or metastasis. On the basis of our series (in which chemotherapy was administered to several patients) and considering that the frequency of LATs with distant recurrence is nonnegligible, ${ }^{21}$ we deem that the further administration of chemotherapy could be effective to control extramediastinal tumor spread, resulting in better OS and CSS. Unfortunately, our data did not allow us to define the best postoperative treatment (radiotherapy or chemotherapy alone or a combination of both). Needless to say, this issue should be better assessed in future clinical trials.

As previously reported, stage III thymomas represent a heterogeneous category of TTs with different pathologic features, such as tumor size or organ involvement. With regard to tumor dimension, Wright and coworkers ${ }^{32}$ demonstrated a worse recurrence rate in tumors larger than $8 \mathrm{~cm}$, confirming a prognostic stratification according to this factor. Similarly, the impact of the level of tumor spread has been rarely evaluated in the literature. Some authors reported a worse OS in cases with vascular invasion. ${ }^{7,33}$ On the other hand, the kind of organ infiltration has not been associated with increased relapse rate. ${ }^{7}$ Given the varying tumor size and the pathologic invasion of mixed mediastinal structures counted for final staging, we evaluated the impact of these 2 factors on outcome to overcome the bias related to stage heterogeneity. In contrast to single-organ invasion, we found that tumor size larger than $5 \mathrm{~cm}$ and pT status were significantly associated with RFS, respectively, at both univariate and multivariate analyses (either in the unmatched or the matched cohort). In particular, we further confirmed the prognostic index of pT category, which has been proposed to manage more accurately "the complexity of different structures that may be involved, either alone or in combination with other." 12 On the basis of these results, we hypothesized that the previously mentioned pathologic features may play a role in the postoperative setting when a decision on the optimal strategy (AT or surveillance) should be performed. We therefore stratified the outcome in the matched cohort according to administration of AT and pT or tumor size. Specifically, AT demonstrated a significant survival advantage in stage III thymomas with a higher level of organ invasion (pT3) and in smaller tumors. On the other hand, this benefit disappeared in those thymomas with tumor size larger than $5 \mathrm{~cm}$, raising the question of which is the best postoperative therapy to use in such cases. Unfortunately, we do not have sufficient data to explain this discrepancy. In our opinion, administration of IT or a tailored AT with different radiotherapy dose or chemotherapy regimens could be administered to improve the outcome after resection of large TTs. We strongly advocate the need for future studies on IT or AT to better assess this issue.

This study has several limitations. First, we performed a retrospective analysis on data collected from centers of different volume activity, expertise, and geographic areas. Second, although histologic specimens were evaluated by pathologists experienced with mediastinal tumors, there was no central pathologic review. Furthermore, the indications for IT and radiologic response to IT were not properly elucidated in our data. In addition, the AT modalities were not standardized among the participating centers. Although lymph node involvement is relatively uncommon in patients with thymoma, ${ }^{12}$ data on pathologic nodal status were not available. On the other hand, the main strength of our study is that it is based on one of the largest patient databases with LATs ever collected. Specifically, the analysis on collaborative retrospective databases offers the opportunity to collect a large amount of patients (in a relatively short period) with rare diseases such as TTs. In fact, whereas the relatively small size of previous studies allowed detection only of prognostic factors with a medium to large effect, larger cohort studies are able to define better any smaller effects on outcome, ${ }^{8,34}$ Furthermore, the participating institutions used a uniform staging system as well as histologic classification. Finally, our cohort is homogenous, as only patients with thymoma were considered, with the exclusion of patients with thymic carcinoma and neuroendocrine TT to avoid confounding biases. 
In conclusion, the optimal multimodality strategy for LATs is still an extremely challenging issue. Our data do not allow us to assess the real prognostic impact of IT in LATs. On the other hand, our analysis indicates that the administration of AT and the completeness of resection represent the most significant outcome predictors. Specifically, AT should be administered whenever possible, especially to those patients with specific pathologic features (pT3 or tumor size $<5 \mathrm{~cm}$ ) who may benefit the most from multimodality treatment. Further studies are needed to confirm these data and to define optimal postoperative therapeutic regimens according to different pathologic cancer characteristics.

\section{Conflict of Interest Statement}

Authors have nothing to disclose with regard to commercial support.

\section{References}

1. Travis WD, Brambilla E, Muller-Hermelink HK, Harris CC, eds. Pathology and Genetics of Tumours of the Lung, Pleura, Thymus and Heart (World Health Organization Classification of Tumours). Lyon: IARC Press; 2004.

2. Ruffini E, Detterbeck F, Van Raemdonck D, Rocco G, Thomas P, Weder W, et al; European Association of Thoracic Surgeons (ESTS) Thymic Working Group. Tumours of the thymus: a cohort study of prognostic factors from the European Society of Thoracic Surgeons database. Eur J Cardiothorac Surg. 2014;46: 361-8.

3. Myojin M, Choi NC, Wright CD, Wain JC, Harris N, Hug EB, et al. Stage III thymoma: pattern of failure after surgery and postoperative radiotherapy and its implication for future study. Int J Radiat Oncol Biol Phys. 2000;46:927-33.

4. Blumberg D, Port JL, Weksler B, Delgado R, Rosai J, Bains MS, et al. Thymoma: a multivariate analysis of factors predicting survival. Ann Thorac Surg. 1995;60: 908-13; discussion 914.

5. Detterbeck FC, Parsons AM. Thymic tumors. Ann Thorac Surg. 2004;77:1860-9.

6. Ruffini E, Mancuso M, Oliaro A, Casadio C, Cavallo A, Cianci R, et al. Recurrence of thymoma: analysis of clinicopathologic features, treatment, and outcome. J Thorac Cardiovasc Surg. 1997;113:55-63.

7. Marulli G, Lucchi M, Margaritora S, Cardillo G, Mussi A, Cusumano G, et al. Surgical treatment of stage III thymic tumors: a multi-institutional review from four Italian centers. Eur J Cardiothorac Surg. 2011;39:e1-7.

8. Korst RJ, Kansler AL, Christos PJ, Mandal S. Adjuvant radiotherapy for thymic epithelial tumors: a systematic review and meta-analysis. Ann Thorac Surg. 2009;87:1641-7.

9. Wright CD, Choi NC, Wain JC, Mathisen DJ, Lynch TJ, Fidias P. Induction chemoradiotherapy followed by resection for locally advanced Masaoka stage III and IVa thymic tumors. Ann Thorac Surg. 2008;85:385-9.

10. Kim ES, Putnam JB, Komaki R, Walsh GL, Ro JY, Shin HJ, et al. A phase II study of a multidisciplinary approach with induction chemotherapy, followed by surgical resection, radiation therapy and consolidation chemotherapy for unresectable malignant thymomas: final report. Lung Cancer. 2004;44:369-79.

11. Koga K, Matsuno Y, Noguchi M, Mukai K, Asamura H, Goya T, et al. A review of 79 thymomas: modification of staging system and reappraisal of conventional division into invasive and non-invasive thymoma. Pathol Int. 1994;44: 359-67.

12. Detterbeck FC, Stratton K, Giroux D, Asamura H, Crowley J, Falkson C, et al; Staging and Prognostic Factors Committee; Members of the Advisory Boards; Participating Institutions of the Thymic Domain. The IASLC/ITMIG Thymic Epithelial Tumors Staging Project: proposal for an evidence-based stage classification system for the forthcoming (8th) edition of the TNM classification of malignant tumors. J Thorac Oncol. 2014;9(9 Suppl 2): S65-72.

13. Ruffini E, Van Raemdonck D, Detterbeck F, Rocco G, Thomas P, Venuta F, European Society of Thoracic Surgeons Thymic Questionnaire Working
Group. Management of thymic tumors: a survey of current practice among members of the European Society of Thoracic Surgeons. J Thorac Oncol. 2011;6:614-23.

14. Kondo K, Monden Y. Therapy for thymic epithelial tumors: a clinical study of 1320 patients from Japan. Ann Thorac Surg. 2003;76:878-84; discussion 884-5.

15. Regnard JF, Magdeleinat P, Dromer C, Dulmet E, de Montpreville V, Levi JF, et al. Prognostic factors and long-term results after thymoma resection. A series of 307 patients. J Thorac Cardiovasc Surg. 1996;112:376-84.

16. Attaran S, Acharya M, Anderson JR, Punjabi PP. Does surgical debulking for advanced stages of thymoma improve survival? Interact Cardiovasc Thorac Surg. 2012;15:494-7.

17. Giaccone G, Musella R, Berretto O, Donadio M, Calciati A. Cisplatin-containing chemotherapy in the treatment of invasive thymoma: report of five cases. Cancer Treat Rep. 1985;69:695-7.

18. Rea F, Marulli G, Di Chiara F, Schiavon M, Perissinotto E, Breda C, et al. Multidisciplinary approach for advanced stage thymic tumors: long-term outcome. Lung Cancer. 2011;72:68-72.

19. Korst RJ, Bezjak A, Blackmon S, Choi N, Fidias P, Liu G, et al. Neoadjuvant chemoradiotherapy for locally advanced thymic tumors: a phase II, multiinstitutional clinical trial. J Thorac Cardiovasc Surg. 2014;147:36-46.e1.

20. Park S, Ahn MJ, Ahn JS, Sun JM, Shim YM, Kim J, et al. A prospective phase II trial of induction chemotherapy with docetaxel/cisplatin for Masaoka stage III/IV thymic epithelial tumors. J Thorac Oncol. 2013;8:959-66.

21. Kondo K. Therapy for thymic epithelial tumors. Gen Thorac Cardiovasc Surg. 2014;62:468-74.

22. Hayes SA, Huang J, Plodkowski AJ, Katzen J, Zheng J, Moskowitz CS, et al. Preoperative computed tomography findings predict surgical resectability of thymoma. J Thorac Oncol. 2014;9:1023-30.

23. Zhu G, He S, Fu X, Jiang G, Liu T. Radiotherapy and prognostic factors for thymoma: a retrospective study of 175 patients. Int J Radiat Oncol Biol Phys. 2004;60:1113-9.

24. Fuller CD, Ramahi EH, Aherne N, Eng TY, Thomas CR Jr. Radiotherapy for thymic neoplasms. J Thorac Oncol. 2010;5(10 Suppl 4):S327-35.

25. Loehrer PJ Sr, Jiroutek M, Aisner S, Aisner J, Green M, Thomas CR Jr, et al. Combined etoposide, ifosfamide, and cisplatin in the treatment of patients with advanced thymoma and thymic carcinoma: an intergroup trial. Cancer. 2001; 91:2010-5.

26. Zhang H, Lu N, Wang M, Gu X, Zhang D. Postoperative radiotherapy for stage I thymoma: a prospective randomized trial in 29 cases. Chin Med J (Engl). 1999; $112: 136-8$.

27. Adams MJ, Lipsitz SR, Colan SD, Tarbell NJ, Treves ST, Diller L, et al. Cardiovascular status in long-term survivors of Hodgkin's disease treated with chest radiotherapy. J Clin Oncol. 2004;22:3139-48.

28. Johansson S, Svensson H, Denekamp J. Timescale of evolution of late radiation injury after postoperative radiotherapy of breast cancer patients. Int $J$ Radiat Oncol Biol Phys. 2000;48:745-50.

29. Omasa M, Date H, Sozu T, Sato T, Nagai K, Yokoi K, et al; Japanese Association for Research on the Thymus. Postoperative radiotherapy is effective for thymic carcinoma but not for thymoma in stage II and III thymic epithelial tumors: The Japanese Association for Research on the Thymus Database Study. Cancer. 2015;121:1008-16. Erratum in: Cancer. 2015;121:2102.

30. Weksler B, Shende M, Nason KS, Gallagher A, Ferson PF, Pennathur A. The role of adjuvant radiation therapy for resected stage III thymoma: a population-based study. Ann Thorac Surg. 2012;93:1822-8; discussion 1828-9.

31. Haniuda M, Morimoto M, Nishimura H, Kobayashi O, Yamanda T, Iida F. Adjuvant radiotherapy after complete resection of thymoma. Ann Thorac Surg. 1992;54:311-5.

32. Wright CD, Wain JC, Wong DR, Donahue DM, Gaissert HA, Grillo HC, et al. Predictors of recurrence in thymic tumors: importance of invasion, World Health Organization histology, and size. J Thorac Cardiovasc Surg. 2005;130:1413-21.

33. Okumura M, Miyoshi S, Takeuchi Y, Yoon HE, Minami M, Takeda SI, et al. Results of surgical treatment of thymomas with special reference to the involved organs. J Thorac Cardiovasc Surg. 1999;117:605-13.

34. Detterbeck F, Youssef S, Ruffini E, Okumura M. A review of prognostic factors in thymic malignancies. J Thorac Oncol. 2011;6(7 Suppl 3):S1698-704.

Key Words: induction therapy, adjuvant therapy, Masaoka, stage III, thymoma, thymic tumors, multimodality treatment, advanced thymoma, TNM 


\section{Discussion}

Dr Benjamin D. Kozower (Charlottesville, Va). Congratulations to you and your group on an excellent presentation. You have used the ESTS thymic database to report on 370 patients with stage III thymomas treated at 37 institutions through a 20 -year period. Obviously, this disease is quite rare, and so it is appropriate to perform the type of study that you have. It is also quite difficult, however, in that you have to account for a wide range of both patient and treatment heterogeneity over a long period. Your primary conclusion is that IT is not associated with improved survival but AT is.

I have 2 questions for you. First, I will start actually with a comment. The IT group in this study has a worse prognosis because, as you stated in the article, there was concern by the surgeon for the ability to do a complete resection, and in fact only $65 \%$ of the patients in the IT group had an R0 resection and half of that group also received postoperative therapy. I am concerned that your Cox model and the propensity score cannot adequately account for this. How do you feel about this, and did you adequately adjust for both disease severity and selection for treatment bias?

Dr Leuzzi. I understand your concerns. The main strength and limitation at the same time of our study is that we considered a great number of patients treated by several surgeons who may face variably a radical thymectomy and different indications for surgery. I think this is the main bias of every large multicentric database. In fact, as I said before, in our study the different strategies were not standardized. In addition, if you see the comparative analysis, the patients undergoing IT were statistically younger, had a worse histologic type, and were more often subjected to incomplete resection. We tried to perform a propensity score match to reduce these biases, and we found that only AT was the strongest factor for the outcome. I think that the removal of the bias related to the surgeon's mindset regarding resectability is too difficult. On the other hand, in our database we have a few data to use to homogenize the sample better. Probably we need further studies to better confirm these data, probably randomized, controlled studies.

Dr Kozower. It is going to be hard to do, obviously, as this is very rare.

My second question is quick. With this study, how is it going to influence how you care for folks when you see them in the clinic, when you see a patient with a large, potentially difficult stage III lesion?

Dr Leuzzi. In my own practice, in my institution, for example, we performed a comparative analysis between patients undergoing IT or immediate surgery. Also in our study we found that patients undergoing immediate surgery had similar survival to those undergoing IT. Regarding our study, we need to consider that in the preoperative setting we should account for the size of the tumor and the organ invasion. With small tumors and apparently resectable tumors, we could go straight to thymectomy first and then AT. On the other hand, larger thymomas might benefit from IT, because IT could reduce the size of the tumor. This results in better resectability and better response to AT, as we also have seen in our analysis reporting that tumors smaller than $5 \mathrm{~cm}$ had a better survival after AT. It is the association of IT with surgery and AT that improves the outcome, not the IT itself. I think, however, that the use of these pathologic features may open the doors to future trials on AT. 


\section{APPENDIX 1. THE EUROPEAN SOCIETY OF THORACIC SURGEONS THYMIC WORKING GROUP}

Khaled Alkattan, ${ }^{\mathrm{a}}$ Alex Arame, ${ }^{\mathrm{b}}$ Majed Refai, ${ }^{\mathrm{c}}$ Caterina Casadio, ${ }^{\mathrm{d}}$ Paolo Carbognani, ${ }^{\mathrm{e}}$ Robert Cerfolio, ${ }^{\mathrm{f}}$ Giovanni Donati, ${ }^{\mathrm{g}}$ Christophoros N. Foroulis, ${ }^{\mathrm{h}}$ Cengiz Gebitekin, ${ }^{\mathrm{i}}$ David Gomez de Antonio, ${ }^{\mathrm{j}}$ Kemp H Kernstine, ${ }^{\mathrm{k}}$ Shaf Keshavjee, ${ }^{1}$ Bernhard Moser ${ }^{\mathrm{m}}{ }^{\mathrm{C}}$ Cosimo Lequaglie, ${ }^{\mathrm{n}}$ Moishe Liberman, ${ }^{\circ}$ Eric Lim, ${ }^{\mathrm{p}}$ Andrew $\mathrm{G}$ Nicholson, ${ }^{\mathrm{p}}$ Loic Lang-Lazdunski, ${ }^{\mathrm{q}}$ Maurizio Mancuso, ${ }^{\mathrm{r}}$ Nasser Altorki, ${ }^{\mathrm{s}}$ Mario Nosotti, ${ }^{\mathrm{t}}$ Nuria M. Novoa, ${ }^{\mathrm{u}}$ Geoffrey Brioude, ${ }^{\mathrm{v}}$ Alberto Oliaro, ${ }^{\mathrm{w}}$ Pier Luigi Filosso, ${ }^{\mathrm{x}}$ Salvatore Saita, ${ }^{\mathrm{x}}$ Marco Scarci, ${ }^{\mathrm{y}}$ Jan Schützner, ${ }^{\mathrm{z}}$ Alberto Terzi, ${ }^{\text {aa }}$ Alper Toker, ${ }^{\text {bb }}$ Hans Van Veer, ${ }^{\text {cc }}$ Marco Anile, ${ }^{\text {dd }}$ Erino Rendina, ${ }^{\text {ee }}$ Luca Voltolini, ${ }^{\mathrm{ff}}$ and Wojciech Zurek. ${ }^{\mathrm{gg}}$

Affiliations: ${ }^{a}$ King Faisal Specialist Hospital, Alfaisal

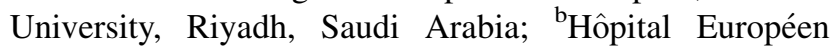
Georges-Pompidou and Hôpital Laennec, Paris, France; ${ }^{\mathrm{c} O s p e d a l i ~ R i u n i t i, ~ A n c o n a, ~ I t a l y ; ~}{ }^{\mathrm{d}}$ University of Eastern Piedmont, Novara, Italy; ${ }^{\mathrm{e}}$ University of Parma, Parma, Italy; ${ }^{\mathrm{f}}$ University of Alabama at Birmingham, Birmingham, Ala; ${ }^{g}$ General Regional Hospital, Aosta, Italy; ${ }^{\mathrm{h}}$ Aristotle University of Thessaloniki, A.H.E.P.A. University Hospital, Thessaloniki, Greece; ${ }^{i}$ Uludag University School of Medicine, Bursa, Turkey; ${ }^{\mathrm{j} H o s p i t a l}$ Universitario Puerta de Hierro Majadahonda, Madrid, Spain; ${ }^{k}$ University of Texas, Southwestern Medical Center and School of Medicine, Tex; ${ }^{1}$ Toronto General Hospital, University of Toronto, Toronto, Canada; ${ }^{\mathrm{m}}$ Medical University of Vienna, Vienna, Austria; ${ }^{\mathrm{n}}$ IRCCS-CROB Centro Riferimento Oncologico della Basilicata, Rionero in Vulture, Italy; ${ }^{\circ}$ Centre Hospitalier de l'Université de Montréal, University of Montreal, Montreal, Canada; ${ }^{\mathrm{p}}$ Royal Brompton and Harefield NHS Foundation Trust and National Heart and Lung Division, Imperial College, London, United Kingdom; ' Guy's Hospital, London, United Kingdom; ${ }^{r}$ SS Antonio e Biagio e Cesare Arrigo Hospital, Alessandria, Italy; ${ }^{\mathrm{s}}$ New York Presbyterian Hospital-Weill Cornell Medical Center, NY; 'IRCCS Fondazione Cà Granda Ospedale Maggiore Policlinico, Milano, Italy; university Hospital of Salamanca, IBSAL, Salamanca, Spain; ${ }^{\vee}$ Hôpital Nord-Aix-Marseille University, Marseille, France; ${ }^{\mathrm{w}}$ Department of Surgery, University of Torino, Torino, Italy; ${ }^{\mathrm{x}}$ Vittorio Emanuele Hospital, Catania, Italy; ${ }^{\mathrm{y}}$ Papworth Hospital NHS Foundation Trust, Papworth Everard, Cambridge, United Kingdom; ${ }^{\mathrm{Z} T h i r d ~ D e p a r t m e n t ~}$ of Surgery, First Faculty of Medicine, Charles University in Prague and University Hospital Motol, Prague, Czech Republic; ${ }^{\text {aa }}$ Thoracic Surgery, Sacred Heart Hospital
Negrar, Verona, Italy; ${ }^{\mathrm{bb}}$ Istanbul University, Istanbul Medical School, Istanbul, Turkey; ${ }^{c c}$ University Hospitals Leuven, Leuven, Belgium; ${ }^{\mathrm{dd}}$ University of Rome SAPIENZA, Policlinico Umberto I, Fondazione Eleonora Lorilard Spencer Cenci, Rome, Italy; ${ }^{e e}$ University of Rome SAPIENZA, Ospedale S. Andrea, Fondazione Eleonora Lorilard Spencer Cenci, Rome, Italy; ${ }^{\mathrm{ff}}$ University Hospital of Siena, Siena, Italy; ${ }^{\mathrm{gg}}$ Medical University of Gdansk, Gdansk, Poland.

\section{APPENDIX 2. LIST OF PARTECIPATING INSTITUTIONS}

King Khalid University Hospital, Riyadh, Saudi Arabia; Hôpital Européen Georges-Pompidou and Hôpital Laennec, Paris, France; Ospedali Riuniti, Ancona, Italy; University of Eastern Piedmont, Novara, Italy; Università di Parma, Italy; Regina Elena National Cancer InstituteIFO, Rome, Italy; University of Alabama, Birmingham, Ala; General Regional Hospital, Aosta, Italy; Aristotle University Medical School, Thessaloniki, Greece; Uludag University School of Medicine, Bursa, Turkey; Hospital Universitario Puerta de Hierro Majadahonda, Madrid, Spain; University of Texas, Southwestern Medical Center and School of Medicine (SW), Dallas, Tex; University of Toronto, Toronto, Ontario, Canada; Medical University of Vienna, Vienna, Austria; IRCCSCROB, Rionero in Vulture, Italy; Centre Hospitalier de l'Université de Montréal, Montréal, Québec, Canada; Royal Brompton Hospital, London, United Kingdom; Guy's Hospital, London, United Kingdom; SS Antonio e Biagio e Cesare Arrigo Hospital, Alessandria, Italy; The New York Hospital, Cornell Medical Centre, New York, NY; IRCCS Fondazione Cà Granda Ospedale Maggiore Policlinico, Milan, Italy; Salamanca University Hospital, Salamanca, Spain; Hôpital Nord-Université de la Méditerranée, Marseille, France; University of Rome Sapienza, Ospedale Sant' Andrea, Rome, Italy; Pascale Institute, Napoli, Italy; University of Torino and AO Città della Salute e della Scienza di Torino, Italy; Vittorio Emanuele Hospital, Catania, Italy; Papworth Hospital NHS Foundation Trust, Papworth Everard, Cambridge, United Kingdom; University Hospital Motol, Prague, Czech Republic; European Institute of Oncology (IEO), Milan, Italy; Ospedale S. Croce Cuneo, Italy; Istanbul Medical Centre, Istanbul, Turkey; University Hospitals Leuven, Leuven, Belgium; University of Rome Sapienza, Policlinico Umberto I, Rome, Italy; Università di Siena, Siena, Italy; University Hospital, Zurich, Switzerland; and Medical University of Gdansk, Gdansk, Poland. 